SOUZA, R.M.; HENZ, G.P.; PEIXOTO, J.R. Incidência de injúrias mecânicas em raízes de mandioquinha-salsa na cadeia de pós-colheita. Horticultura Brasileira, Brasília, v. 21, n. 4, p. 712-718, outubro-dezembro 2003.

\title{
Incidência de injúrias mecânicas em raízes de mandioquinha-salsa na cadeia de pós-colheita ${ }^{1}$
}

\author{
Roberto Marques Souza ${ }^{2}$; Gilmar Paulo Henz ${ }^{3}$ José Ricardo Peixoto² \\ ${ }^{2}$ Faculdade de Agronomia e Veterinária, UnB, Brasília-DF; ${ }^{3}$ Embrapa Hortaliças, C. Postal 218, 70359-970 Brasília-DF; E-mail: \\ gilmar@cnph.embrapa.br
}

\section{RESUMO}

O tamanho e a aparência das raízes de mandioquinha-salsa são os principais atributos de qualidade na comercialização, e os danos mecânicos diminuem sua durabilidade e valor como mercadoria. $\mathrm{O}$ objetivo deste trabalho foi caracterizar e avaliar a incidência de injúrias mecânicas em raízes de mandioquinha-salsa em cinco etapas do manuseio pós-colheita, dividido em colheita, beneficiamento (antes e após a lavação), atacado e varejo. A etapa da colheita foi avaliada em Castro(PR), o beneficiamento nas lavouras de Tapiraí(SP), atacado na CEAGESP(SP) e o varejo em supermercados da grande São Paulo. Em cada etapa foram selecionadas ao acaso 110 raízes, em dez amostragens (repetições) em locais e épocas diferentes, entre março/2000 e junho/2001. As injúrias mecânicas foram categorizadas em quatro tipos principais: abrasão, ruptura parcial, rachadura e quebra das raízes. Como as lesões superficiais causadas pela abrasão apresentaram grande variação na extensão dos danos, foi elaborada uma escala de cinco notas $(1=$ sem lesão; $5=>40 \%$ superfície lesionada) para facilitar a avaliação. As lesões superficiais causadas por abrasão foram o tipo de injúria mecânica com maior incidência em todas as etapas do manuseio, sendo $13,3 \%$ no produtor, $19,7 \%$ nas raízes sem lavar, $24,9 \%$ nas raízes lavadas, $47,2 \%$ no atacado, chegando a $78,9 \%$ no varejo. $\mathrm{O}$ atacado foi a etapa em que constatou-se a maior incidência de outros tipos de injúrias (ruptura, $7,6 \%$; rachadura, $4,2 \%$; quebra, $10,6 \%$ ). O ponto crítico para a incidência de injúrias mecânicas ocorreu entre as etapas beneficiamentoatacadista, provavelmente devido à embalagem (caixa de madeira do tipo "K") e ao transporte inadequados.

Palavras-chave: Arracacia xanthorrhiza, dano mecânico, lesões, ferimentos.

\begin{abstract}
Incidence of mechanical injury in arracacha roots at the postharvest handling system

Size and appearance are the most important quality characteristics of arracacha roots. The aim of this experiment was to determine the main types and the incidence of mechanical injuries in arracacha roots and evaluate its incidence at the different stages of the postharvest handling system used in Brazil. Evalution was carried out during five steps of the postharvest handling system (after harvest; packinghouse, before and after washing; wholesale and retail markets) were verified. At each step, 110 roots were taken at random in ten samples (replications) at different places during March 2000 to June 2001. Four main types of mechanical damage were identified in arracacha roots: abrasion; partial rupture; splitting; and break. Superficial lesions caused by abrasion were the predominant mechanical injury and showed great variation, so an abrasion rating scale ( $1=$ no lesion; $5=>40 \%$ of lesions) was used. Increasing levels of abrasion were recorded as the arracacha roots flowed through the postharvest chain, reaching $13.3 \%$ of the roots at the farm; $19.7 \%$ before washing and $24.9 \%$ after washing at the packinghouse; $47.2 \%$ at the wholesale market; and $78.9 \%$ at the retail market. The incidence of other types of mechanical damage was higher at the wholesale market ( $7.6 \%$ of rupture, $4.2 \%$ of spliting, $10.6 \%$ of broken roots). The critical point for the incidence of mechanical damage at the postharvest chain occurred between the packinghouse and the wholesale market, probably due to inadequate packing in wooden boxes and rough handling.
\end{abstract}

Keywords: Arracacia xanthorrhiza, Peruvian carrot, mechanical damage, lesions.

(Recebido para publicação em 4 de setembro de 2002 e aceito em 10 de outubro de 2003)

\begin{abstract}
A manutenção da qualidade de pro dutos hortícolas depende da coordenação e da integração cuidadosa de várias etapas do manuseio pós-colheita, desde a colheita até seu consumo (Sargent, 1995). Durante a execução das operações do manuseio podem ocorrer vários problemas que reduzem a disponibilidade e a qualidade de frutas e hortaliças, como processos fisiológicos (transpiração, respiração), doenças, danos mecânicos, entre outros (FAO, 1991; Wills et al., 1998).
\end{abstract}

As injúrias mecânicas são a causa primária de perdas pós-colheita para alguns produtos hortícolas, e podem ocorrer em qualquer ponto da cadeia de produção, beneficiamento e comercialização (Peleg, 1985; Kays, 1991). Em muitos casos, os principais danos ocorrem na operação de colheita, recolhimento e transporte do produto do campo até o galpão de beneficiamento; em outros, os pontos principais na incidência de injúrias mecânicas podem ser as operações de seleção e classificação ou a passagem do produto por equipamentos inadequados (Peleg, 1985; Sargent et al., 1989a e 1989b). As injúrias mecânicas podem ser reduzidas a um nível aceitável quando todo o sistema de manuseio pós-colheita é avaliado, desde a colheita até o consumidor (Peleg, 1985; Sargent, 1995).

As injúrias mecânicas podem resultar em deformações plásticas, rupturas superficiais chegando até a destruição dos tecidos vegetais. Além dos danos diretos, a incidência de ferimentos em

1 Parte da dissertação de mestrado apresentada à Faculdade de Agronomia e Veterinária da Universidade de Brasília (UnB) pelo primeiro autor. 
frutas e hortaliças pode levar a um aumento de doenças de pós-colheita e alterações fisiológicas e químicas, como a respiração, síntese de etileno, cor, aroma, sabor, textura e outros (Honório \& Moretti, 2002). As principais causas de injúrias mecânicas em produtos hortícolas são forças externas de vibração, compressão e impacto (Kays, 1991; Wills et al., 1997), que podem causar diferentes tipos de lesões, como abrasões, cortes, rupturas, amassamentos e injúrias internas (Sargent et al., 1989a e 1989b; Chitarra \& Chitarra, 1990). A injúria por vibração em geral ocorre durante o transporte, resultando em lesões que podem variar de marcas superficiais de abrasão até a remoção substancial de tecido. Os ferimentos por impacto são causados pela queda dos produtos e das embalagens e outros tipos de choques.

Um número significativo de produtos hortícolas apresenta problemas de injúrias mecânicas. Algumas frutas e hortaliças têm alto teor de água e/ou uma estrutura muito delicada, como pêra e mamão, sendo altamente suscetíveis a ferimentos. Outros são mais resistentes, mas pelo fato de serem transportados e/ ou armazenados por algum período de tempo, a manutenção de sua integridade física é muito importante, como ocorre com a batata no Hemisfério Norte.

Nos Estados Unidos, em uma série de artigos publicados sobre perdas póscolheita de diversas frutas e hortaliças por pesquisadores do ARS/USDA entre 1973 e 1974, considerou-se que as perdas causadas diretamente por injúrias mecânicas variaram de $0,2 \%$ em laranja até $8,3 \%$ em uva no mercado varejista e para o consumidor (Kays, 1991). Em maçã, determinou-se que a incidência de puntuações na superfície dos frutos aumentou progressivamente à medida que o produto foi movimentado do pomar (26\%) para o galpão de beneficiamento $(30 \%)$, para o atacado (36\%), alcançando 50\% nas gôndolas das quitandas (Ceponis et al., 1962). Cappellini et al. (1987) determinaram as principais desordens na cenoura comercializada entre 1972 e 1985 em Nova York, e as cargas afetadas por injúrias mecânicas (raízes rachadas e quebradas) variaram de 16,4\% (pré-emba- lada, origem Texas) a 52,4\% (granel, origem Canadá). Em tubérculos de batata, os tipos de injúrias mecânicas mais comuns são esfoladuras, cortes, compressões e escurecimentos por impacto (Thornton, 2001). Em raízes de cenoura, rachaduras e quebras são dois tipos de injúrias muito importantes (Cantwell et al., 1991). A incidência de danos por ferimentos em batata durante a operação de colheita é determinada por vários fatores, como as condições do solo e do tubérculo, temperatura e método de colheita (Smith, 1977). Os danos mecânicos foram identificados como a principal causa de perda de qualidade no mercado atacadista e varejista de vários produtos, como alface, batata, morango, maçã e pêssego (Wright \& Billeter, 1975).

No Brasil, são poucos os estudos sobre a incidência de injúrias mecânicas em hortaliças na cadeia de pós-colheita. Em batata, danos por impacto na colheita provocaram perdas de $10,7 \% \mathrm{e}$ $6,9 \%$ em tubérculos das cvs. Achat e Baraka, respectivamente, após oito dias (Silva \& Márton, 1993). As perdas ocasionadas por injúrias em batata também dependem do método de colheita, e variaram de 2,3\% (arrancador) e 9,6\% (enxada) após sete dias (Silva, 1994). Em raízes de cenoura comercializadas em Brasília no primeiro semestre de 1998 , 9,5\% apresentaram danos mecânicos, aumentando para $34,7 \%$ na porção descartada pelo supermercado, sem considerar as lesões superficiais (Lana et al., 1999a). Em outro levantamento em frutos de pimentão, os danos mecânicos foram a principal causa de perdas, alcançando $48 \%$ de incidência no varejo (Lana et al., 1999b). Em tomate, a incidência de injúrias mecânicas nos frutos variou de acordo com o acondicionamento e transporte dos frutos em vários tipos de embalagens, sendo que caixas plásticas causaram mais abrasões e cortes, caixas de papelão ondulado provocaram mais amassamentos e caixas de madeira do tipo " $\mathrm{K}$ " danos mais graves e profundos devido à aspereza de sua superfície (Castro et al., 2001).

A mandioquinha-salsa apresenta vários problemas pós-colheita, principalmente sua alta perecibilidade e rápida deterioração. De uma maneira geral, considera-se que a vida de prateleira das raízes é de apenas 2-3 dias quando mantidas sem refrigeração e sem embalagem. A incidência de injúrias mecânicas é uma das causas mais importantes de perdas pós-colheita porque afeta diretamente a aparência do produto e acelera diversos processos fisiológicos, como a desidratação e a respiração. Os tipos e a magnitude da incidência de injúrias mecânicas em raízes de mandioquinha-salsa ainda não foram devidamente avaliados no mercado brasileiro, principalmente levando-se em consideração as condições de produção, beneficiamento e comercialização. No beneficiamento, são descartadas raízes que apresentam formato irregular e defeitos graves, como podridão-mole, brocadas, rachaduras e quebras (CEAGESP, 2002). No varejo, as lesões superficiais tornam-se mais visíveis e escurecidas após 1-2 dias de exposição, sendo uma das causas de descarte das raízes.

As lesões superficiais das raízes de mandioquinha-salsa podem ser avaliadas por escalas diagramáticas, muito usadas em fitopatologia para a avaliação de doenças (Reifschneider et al., 1984; Boff et al., 1991; Stonehouse, 1994; Amorim, 1995; Mello et al., 1997). As escalas consistem basicamente em representações ilustradas de plantas com sintomas de diferentes níveis de severidade (Stonehouse, 1994; Amorim, 1995). A construção de escalas diagramáticas deve seguir alguns procedimentos básicos, como a aplicação da lei de acuidade visual, conhecida como lei de Weber-Fechner, em que considera-se que o estímulo proporcionado pelos sintomas de uma doença deve crescer exponencialmente para que a vista humana seja capaz de diferenciálos. Esta lei é muito importante para a determinação dos intervalos da escala proposta, sendo que o limite superior da escala deve corresponder à quantidade máxima da doença observada a campo. A determinação da quantidade real de doença no campo e sua representação na escala devem ter alta precisão e a escala proposta deve ser validada (Stonehouse, 1994; Amorim, 1995).

No Brasil são adotados diferentes sistemas de manuseio pós-colheita da mandioquinha-salsa, de acordo com a 
região, época do ano e volume colhido. O sistema de manuseio pós-colheita da mandioquinha-salsa comercializada na CEAGESP, em São Paulo, pode ser considerado como o mais representativo pelo volume do produto e por sua grande importância econômica e pode ser dividido em cinco etapas: (1) colheita; (2) beneficiamento; (3) atacado; (4) varejo; (5) consumidor (Henz, 2001; Souza, 2001). O mercado paulista é abastecido pelos estados do Paraná e Minas Gerais. Depois de colhidas, as raízes são acondicionadas em caixas plásticas de $32-34 \mathrm{~kg}$ e transportadas por caminhões até galpões de beneficiamento nos municípios de Piedade e Tapiraí-SP. As raízes são lavadas, classificadas e embaladas em caixas de madeira do tipo "K" novas e transportadas por caminhão até a CEAGESP, distante $130 \mathrm{~km}$ (Henz, 2001; Souza, 2001).

Os objetivos deste trabalho foram definir os tipos mais importantes de injúrias mecânicas em raízes de mandioquinha-salsa e avaliar e quantificar sua incidência na cadeia de manuseio pós-colheita.

\section{MATERIAL E MÉTODOS}

\section{Avaliação da incidência de tipos de injúrias mecânicas}

Foram coletadas raízes que apresentavam diferentes tipos de injúrias mecânicas nas distintas etapas do manuseio pós-colheita, como colheita, transporte, beneficiamento, comercialização no atacado e no varejo do estado de São Paulo. Estas raízes foram examinadas individualmente para categorizar o tipo de injúria mecânica de acordo com sua extensão, profundidade e dano ao tecido. Um critério adicional na categorização dos tipos de injúrias mecânicas nas raízes foi a rapidez e facilidade de reconhecimento para a avaliação por exame visual.

A avaliação de injúria mecânica foi realizado no sistema de manuseio póscolheita das raízes de mandioquinha-salsa adotado nas beneficiadoras da região de Piedade e Tapiraí-SP e comercializadas na CEAGESP, em São Paulo-SP. A cadeia de pós-colheita foi dividida em cinco etapas para efeito de amostragem das raízes: (1) produtores da região de Castro-PR, após a colheita em raízes acondicionadas em caixas plásticas; (2) beneficiamento, em raízes sem lavar acondicionadas em caixas plásticas de $32-34 \mathrm{~kg}$ transportadas por $350 \mathrm{~km}$ em caminhões até Tapiraí-SP; (3) beneficiamento, em raízes lavadas no sistema adotado na região de TapiraíSP; (4) atacado (CEAGESP, São Paulo-SP); e (5) varejo, coletando-se apenas raízes vendidas a granel em gôndolas de supermercados da região metropolitana de São Paulo. Para uniformizar as amostras, foram selecionadas raízes de tamanho médio (10-13 cm de comprimento, $3-3,5 \mathrm{~cm}$ de diâmetro), correspondentes às classes $2 \mathrm{~A}$ e $3 \mathrm{~A}$. Em cada uma das cinco etapas do manuseio pós-colheita foram selecionadas ao acaso 110 raízes, em dez amostragens (repetições) em épocas diferentes no período entre março/2000 e junho/2001. Cada raiz foi avaliada individualmente, examinando-se todas as faces, categorizando-se em um dos seguintes tipos de lesão: quebra, rachadura, ruptura e abrasão ( $>5 \%$ da superfície da raiz com lesões superficiais). Raízes sem nenhum tipo das lesões descritas anteriormente e com menos de 5\% de lesão superficial foram consideradas aparentemente intactas.

Construção de uma escala de notas para avaliação de lesão superficial

A escala de notas para aferição de lesões superficiais foi feita tomando-se ao acaso 50 raízes de mandioquinhasalsa de tamanho médio, com aproximadamente $12 \mathrm{~cm}$ de comprimento, provenientes da CEAGESP, em São Paulo-SP. Para cada uma das raízes, determinou-se a área superficial total ajustando-se um plástico de cor preta o mais próximo possível da forma e tamanho da raiz e recortando-se com uma tesoura o excedente. A área superficial total de cada raiz, representada pelo molde em plástico, foi estimada em medidor de área foliar Li-Cor Inc. modelo 3100.

Para determinar a área lesionada foram selecionadas outras 50 raízes de tamanho médio que apresentavam injúrias mecânicas superficiais com diferentes níveis. Estas raízes foram envolvidas em plástico transparente da mesma maneira como descrito anteriormente, sendo que as áreas das lesões superficiais fo- ram coloridas com caneta para retroprojetor, reproduzindo-se a mesma forma e tamanho. As áreas correspondentes às lesões superficiais também foram estimadas em um medidor de área foliar Li-Cor Inc. modelo 3100, calculando-se a porcentagem de área lesionada de cada raiz. Para a construção da escala de notas, considerou-se a aplicação da Lei de Weber \& Flechner (Amorim, 1998) e foram determinados intervalos de incidência de lesões correspondentes a cinco notas. A escala foi devidamente validada antes de ser utilizada (Stonehouse, 1994; Souza, 2001).

\section{Avaliação da incidência de lesões} superficiais

A avaliação da incidência de lesões superficiais foi realizada examinandose cada raiz em duas faces distintas e atribuindo-se uma nota média, de acordo com a escala de notas descrita anteriormente. $\mathrm{O}$ experimento foi realizado do mesmo modo como descrito anteriormente para a incidência dos tipos de injúrias mecânicas, dividindo-se a cadeia de pós-colheita da mandioquinhasalsa em cinco segmentos de amostragem. Em cada uma das etapas foram examinadas 110 raízes selecionadas ao acaso em dez amostras distintas avaliadas no período entre março/2000 e junho/2001. Calculou-se a nota média para cada etapa pela fórmula $\mathrm{S}=(\operatorname{nota} 1 \times n) \ldots+($ nota $5 \times n) / n$ total, onde $n=$ número de raízes.

\section{RESULTADOS E DISCUSSÃO}

Durante a comercialização, as raízes de mandioquinha-salsa amostradas apresentaram vários tipos de injúrias mecânicas, podridão-mole ("mela") causada por Erwinia e outras alterações na aparência das raízes, provavelmente causadas pela perda de matéria fresca. As injúrias mecânicas nas raízes de mandioquinha-salsa foram determinadas em pontos chave do manuseio póscolheita, como indicado por Sargent (1995), em etapas identificadas em um trabalho preliminar (Henz, 2001; Souza, 2001). As injúrias mecânicas também podem ser consideradas como uma causa primária de perdas em mandioquinha-salsa, e como constatado para outros produtos hortícolas, po- 
dem ocorrer em qualquer ponto da cadeia de pós-colheita (Peleg, 1985; Kays, 1991; FAO, 1993).

\section{Determinação dos tipos de injúri- as mecânicas}

Foram identificados quatro tipos principais de injúrias mecânicas em raízes de mandioquinha-salsa, categorizadas como abrasão, ruptura, rachadura e quebra (Kays, 1991; Wills et al., 1997). A abrasão caracteriza-se por um rompimento da epiderme resultante da fricção das raízes com uma superfície áspera, destruindo as camadas mais externas do tecido, como uma descamação. A lesão classificada como ruptura é mais profunda e extensa, resultante de uma força externa que causa cortes e rompimento de várias camadas de células (Wills et al., 1997). A quebra é a separação completa da raiz em duas ou mais partes, causada por queda, pressão ou outro tipo de força externa. A rachadura pode ser causada por uma pressão na raiz, como forças exercidas sobre as embalagens de madeira e também por quedas das raízes (Kays, 1991; Wills et al., 1997).

A norma de classificação da mandioquinha-salsa elaborada pelo Centro de Qualidade em Horticultura (CEAGESP, 2002) inclui rachaduras como defeito grave e os danos mecânicos graves $(>10 \%$ superfície lesionada e $>3 \mathrm{~mm}$ profundidade) e leves $(<10 \%$ superfície e $<3 \mathrm{~mm}$ profundidade) como defeitos variáveis. Os tipos de lesões identificados em raízes de mandioquinha-salsa são resultantes de forças de vibração, compressão e impacto, as principais causas de injúrias mecânicas em frutas e hortaliças (Kays, 1991; Wills et al., 1997). Como as raízes de mandioquinha-salsa foram avaliadas externamente, não foram observadas injúrias internas, muito comuns em frutos de textura menos dura, como o tomate (Sargent et al., 1989a e 1989b), geralmente causadas por compressão e quedas.

Os danos mecânicos foram considerados como a principal causa de perda de qualidade no atacado e varejo de diferentes produtos, como alface, batata, morango, maçã e pêssego (Wright \& Billeter, 1975). Em cenoura, a incidência de raízes quebradas e rachadas va- riou de $16,4 \%$ (pré-embalada) a 52,4\% (granel) das cargas recebidas no mercado de Nova York (Cappellini et al., 1987). Quebras e rachaduras são dois tipos de injúrias mecânicas muito importantes em raízes de cenoura (Cantwell et al., 1991). No Distrito Federal, os danos mecânicos foram a principal causa de perda em frutos de pimentão em supermercados, alcançando 48\% de incidência (Lana et al., 1999b), e em raízes de cenoura os danos mecânicos foram responsáveis por $34,7 \%$ da porção descartada (Lana et al., 1999a). Em frutos de tomate cv. Santa Clara, a incidência de injúrias mecânicas foi associado ao tipo de embalagem utilizada, sendo que caixas plásticas causaram mais abrasões e cortes, caixas de papelão ondulado provocaram mais amassamentos e caixas de madeira do tipo " $\mathrm{K}$ " danos mais graves e profundos (Castro et al., 2001).

Incidência de injúrias mecânicas na cadeia de pós-colheita

Houve um efeito cumulativo dos danos mecânicos avaliados ao longo da cadeia de manuseio pós-colheita, com alta incidência de raízes injuriadas no atacado e varejo, diferindo estatisticamente das demais etapas (Tabela 1). A incidência de lesões de todos os tipos (abrasão, quebra, rachadura, ruptura) foi crescente à medida que as raízes passavam pelas diferentes etapas do manuseio (Tabela 1), sendo diferente estatísticamente entre as etapas de beneficiamento (raízes lavadas) e atacado. As lesões superficiais causadas por abrasão foram o tipo de injúria mecânica com maior incidência em todas as etapas do manuseio, alcançando 13,3\% no produtor, $19,7 \%$ nas raízes sem lavar, $24,9 \%$ nas raízes lavadas, $45,9 \%$ no atacado e $78,9 \%$ no varejo (Tabela 1 ).

\section{Produtor}

As operações de colheita, coleta e acondicionamento das raízes em contentores plásticos e recolhimento das caixas e transporte do campo até a sede da propriedade causaram uma incidência média de lesões em $20,5 \%$ das raízes. Aparentemente, a colheita manual ou semi-mecanizada da mandioquinha-salsa causam poucos danos diretos às raízes. Em batata, danos por impacto na colheita provocaram perdas de $10,7 \% \mathrm{e}$
$6,9 \%$ em tubérculos das cvs. Achat e Baraka, respectivamente, após oito dias (Silva \& Márton, 1993). A embalagem e o transporte das caixas plásticas do campo até a sede da propriedade e desta até as beneficiadoras podem causar danos mecânicos porque as caixas têm excesso de raízes e o empilhamento das caixas na carreta tracionada por trator no campo ou no caminhão durante o transporte é inadequado. As bordas das caixas podem ficar diretamente sobre as raízes da caixa posicionada abaixo, causando diferentes tipos de lesões. Nesta etapa, as raízes podem sofrer danos por compressão, impacto e abrasão. A incidência de danos por ferimentos em raízes e tubérculos durante a operação de colheita é determinada por vários fatores, como as condições do solo, temperatura e método de colheita, como determinado para tubérculos de batata (Smith, 1977).

\section{Beneficiamento}

Durante o beneficiamento, a incidência de injúrias mecânicas não é significativa, apesar da movimentação das raízes que são transferidas dos contentores plásticos para as redes e depois colocadas em uma mesa de seleção e acondicionadas em caixas. Não constatou-se diferença estatística significativa para a incidência dos diferentes tipos de lesões entre as etapas de raízes antes e depois da lavação (Tabela 1). O sistema adotado pelas beneficiadoras de Tapiraí-SP praticamente não causa injúrias mecânicas porque as raízes são movimentadas suavemente em tanques d'água envoltas em redes de algodão (Henz, 2001; Souza, 2001).

\section{Comercialização}

No atacado, 69,6\% das raízes apresentaram lesões, com uma incidência de $7,6 \%$ das raízes com rupturas, $4,2 \%$ de rachaduras e $10,6 \%$ de quebras. Com exceção do dano por abrasão, a incidência de outros tipos de injúrias (quebra, rachadura, ruptura) foi a mais elevada de todas as etapas avaliadas (Tabela 1). No varejo, a incidência de raízes com estes defeitos foi menor porque geralmente são descartadas periodicamente por funcionários a partir do primeiro dia de exposição, sendo que o tipo de lesão predominante foi abrasão $(78,9 \%$ das raízes). Quando as raízes chegam ao 
Tabela 1. Incidência de tipos de injúrias mecânicas em raízes de mandioquinha-salsa em cinco etapas da cadeia de manuseio pós-colheita em São Paulo. Brasília-DF, Embrapa Hortaliças/UnB-FAV, 2000-2001.

\begin{tabular}{|c|c|c|c|c|c|c|}
\hline \multirow{2}{*}{ Etapa ${ }^{1}$} & \multirow{2}{*}{$\begin{array}{c}\text { Raízes } \\
\text { intactas (\%) }\end{array}$} & \multirow{2}{*}{$\begin{array}{c}\begin{array}{c}\text { Raízes } \\
\text { lesionadas } \\
(\%)\end{array} \\
\end{array}$} & \multicolumn{4}{|c|}{ Incidência de tipos de danos $(\%)^{2}$} \\
\hline & & & Abrasão & Quebra & Rachad. & Ruptura \\
\hline Produtor & $79,5 \mathrm{a}$ & $20,5 b$ & $13,3 \mathrm{c}$ & $5,7 a b$ & $0 \mathrm{~b}$ & $1,5 b$ \\
\hline Benef./sem lavar & $75,0 \mathrm{a}$ & $25,0 \mathrm{~b}$ & $19,7 \mathrm{c}$ & $3,5 \mathrm{~b}$ & $0 \mathrm{~b}$ & $1,8 \mathrm{~b}$ \\
\hline Benef./lavadas & $69,0 \mathrm{a}$ & $31,0 \mathrm{~b}$ & $24,9 \mathrm{c}$ & $3,9 \mathrm{~b}$ & $0 \mathrm{~b}$ & $2,2 \mathrm{~b}$ \\
\hline Atacado & $30,4 \mathrm{~b}$ & 69,6 a & $47,2 \mathrm{~b}$ & $10,6 \mathrm{a}$ & $4,2 \mathrm{a}$ & $7,6 \mathrm{a}$ \\
\hline Varejo & $11,0 \mathrm{~b}$ & $89,0 \mathrm{a}$ & $78,9 a$ & $4,7 a b$ & $3,5 \mathrm{a}$ & $1,9 \mathrm{~b}$ \\
\hline
\end{tabular}

${ }^{1}$ Etapa do manuseio: Benef.= beneficiador, antes e depois da lavação das raízes;

${ }^{2}$ Tipos de dano: abrasão= lesão superficial; rachad.= raízes rachadas; quebradas e com rupturas parciais;

${ }^{3}$ Médias seguidas pela mesma letra nas colunas não diferem entre si pelo teste de Tukey $(5 \%)$.

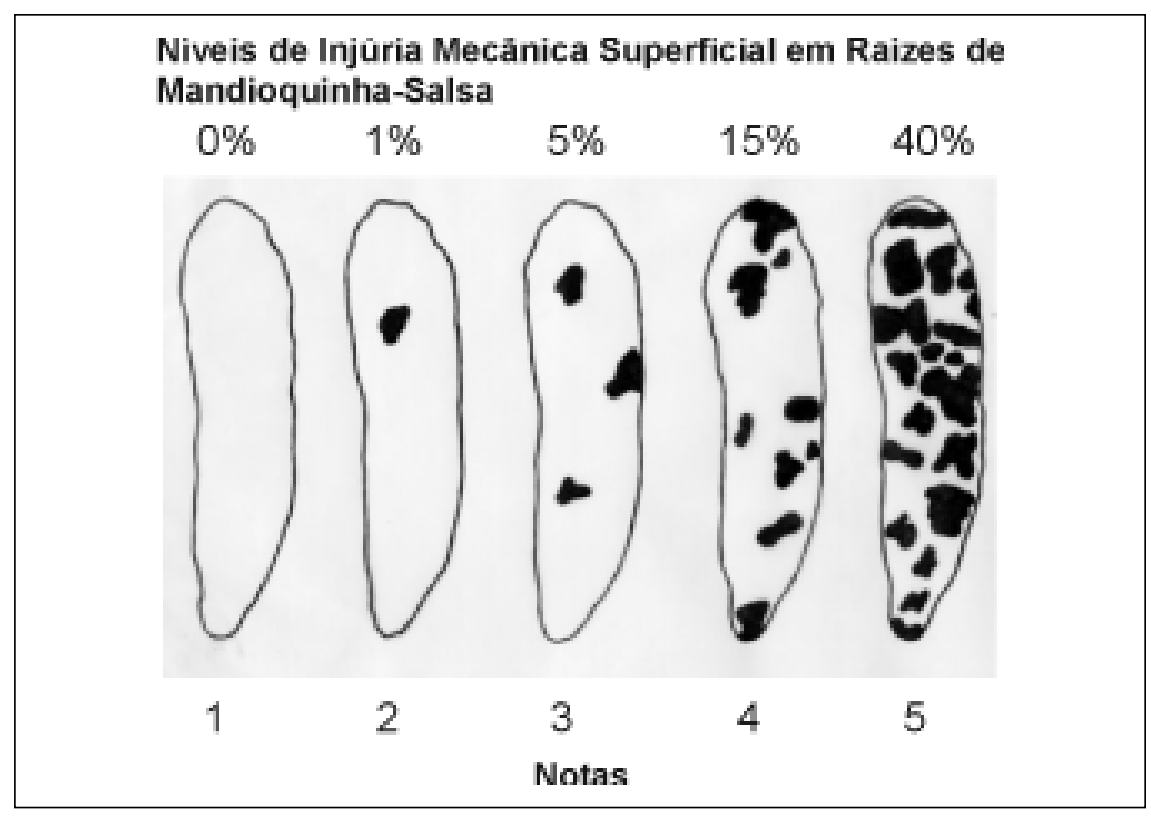

Figura 1. Escala de notas (1-5) para avaliação de lesão superficial causada por abrasão em raízes de mandioquinha-salsa. Brasília-DF, Embrapa Hortaliças/UnB-FAV, 2000-2001.

varejo, as lesões superficiais causadas pela abrasão tornam-se mais visíveis devido à perda de matéria fresca e à suberização das lesões.

A incidência de injúrias mecânicas em hortaliças depende de uma série de fatores, tais como tipo de produto, formato do órgão, temperatura, status hídrico e sistema de manuseio. Em tubérculos de batata produzidos nos Estados Unidos, os tipos de injúrias mecânicas mais comuns são esfoladuras, cortes, compressões e escurecimentos por impacto (Thornton, 2001). Em raízes de cenoura, rachaduras e quebras podem ser os danos mecânicos mais relevantes (Cantwell et al., 1991). À medida que os produtos hortícolas são movimenta- dos do campo até a comercialização no varejo, aumenta a probabilidade de ocorrer um efeito acumulativo da incidência de injúrias mecânicas, como constatado por Sargent et al. (1989a, 1989b) em frutos de tomate produzidos na Flórida, e por Ceponis et al. (1962) em maçã. No caso da mandioquinha-salsa, o ponto crítico da cadeia em relação à incidência de danos mecânicos nas raízes situa-se entre as etapas beneficiador e atacado. Para facilitar e agilizar a avaliação de injúrias mecânicas, Sargent (1995) recomenda a definição do tipo de dano mais importante para cada produto hortícola. No caso da mandioquinha-salsa, o tipo mais comum de injúria mecânica foi a lesão superfi- cial causada por abrasão.

Elaboração de uma escala de notas para abrasão

A elaboração da escala de notas para avaliar a severidade da abrasão em raízes de mandioquinha-salsa foi baseada nos mesmos princípios das escalas utilizadas para avaliar doenças em plantas (Reifschneider et al., 1984; Boff et al., 1991; Stonehouse, 1994; Amorim, 1995; Mello et al., 1997).

A porcentagem média de área lesionada das 50 raízes foi de $22,3 \%$, variando de 0,5 a $45 \%$. A definição das porcentagens de área lesionada superficial e os intervalos entre as notas foram baseados nos princípios da lei de WeberFechner (Stonehouse, 1994; Amorim, 1995). A escala foi elaborada com cinco notas (1-5), com as seguintes porcentagens de área lesionada: $1=$ raiz intacta, sem lesões; $2=1 \%$ de área lesionada; $3=5 \% ; 4=15 \% ; 5=>40 \%$ (Figura 1 ). Os intervalos entre as áreas lesionadas determinadas para cada uma das notas foram adequados para separar na prática os diferentes níveis de injúria e a escala foi devidamente validada antes de ser utilizada (Stonehouse, 1994; Amorim, 1995; Souza, 2001).

A escala mostrou-se de fácil uso, tornando a avaliação da severidade de injúria mecânica superficial das raízes mais rápida, eficiente e acurada (Souza, 2001). As lesões tornam-se mais visíveis $24 \mathrm{~h}$ após a ocorrência do dano mecânico pela diferença de coloração entre a parte intacta e o tecido danificado, geralmente escurecido pela perda de água e outros processos fisiológicos. 
Esta escala também pode ser utilizada na avaliação de injúrias mecânicas superficiais em raízes de cenoura.

Avaliação de lesões superficiais na cadeia de pós-colheita

Houve pequena incidência de lesões superficiais nas raízes nas etapas compreendidas entre o produtor e o beneficiamento, aumentando significativamente durante a comercialização. Após a colheita, as raízes alcançaram nota média $=1,2$, no beneficiamento as raízes sem lavar apresentaram nota média $=1,1$ e as raízes lavadas nota média $=$ 1,2 , não diferindo estatisticamente entre si. No atacado, as raízes apresentaram nota média $=2,3$ e no varejo alcançaram nota média $=3,1$, diferindo estatisticamente entre si e com as demais etapas. A maior parte das raízes não apresentou lesões superficiais (nota 1) nas três primeiras etapas avaliadas (produtor, antes e depois da lavação), variando de $85 \%$ a $90 \%$ de incidência (Figura 2). Apenas $8 \%$ a $10 \%$ das raízes apresentaram $1 \%$ de lesões superficiais (nota 2) nestas três primeiras etapas da cadeia de pós-colheita (Figura 2). A incidência de lesões superficiais aumenta drasticamente nas etapas de comercialização. No atacado, $68 \%$ das raízes apresentaram de $1 \%$ a $5 \%$ de sua superfície com lesões superficiais (notas 2 e 3), e $8 \%$ apresentaram lesões mais extensas (Figura 2). No varejo, $41 \%$ das raízes foram categorizadas na nota 4 , que corresponde a $15 \%$ de área lesionada e $4 \%$ das raízes apresentaram lesões com $40 \%$ da área lesionada (Figura 2).

As lesões superficiais causadas pela abrasão não causam danos tão drásticos nas raízes quanto às quebras, rachaduras e rupturas, mas afetam diretamente o valor comercial da mandioquinha-salsa porque a aparência fica comprometida. À medida que as raízes vão perdendo matéria fresca em ambientes de comercialização sem refrigeração, as lesões superficiais vão tornando-se mais visíveis e diferenciadas do tecido intacto. $\mathrm{O}$ defeito variável definido como escurecimento pela norma de classificação da mandioquinha-salsa proposta pela CEAGESP (2002) é ocasionado pela abrasão. Estas lesões superficiais podem tornar-se escuras após sua

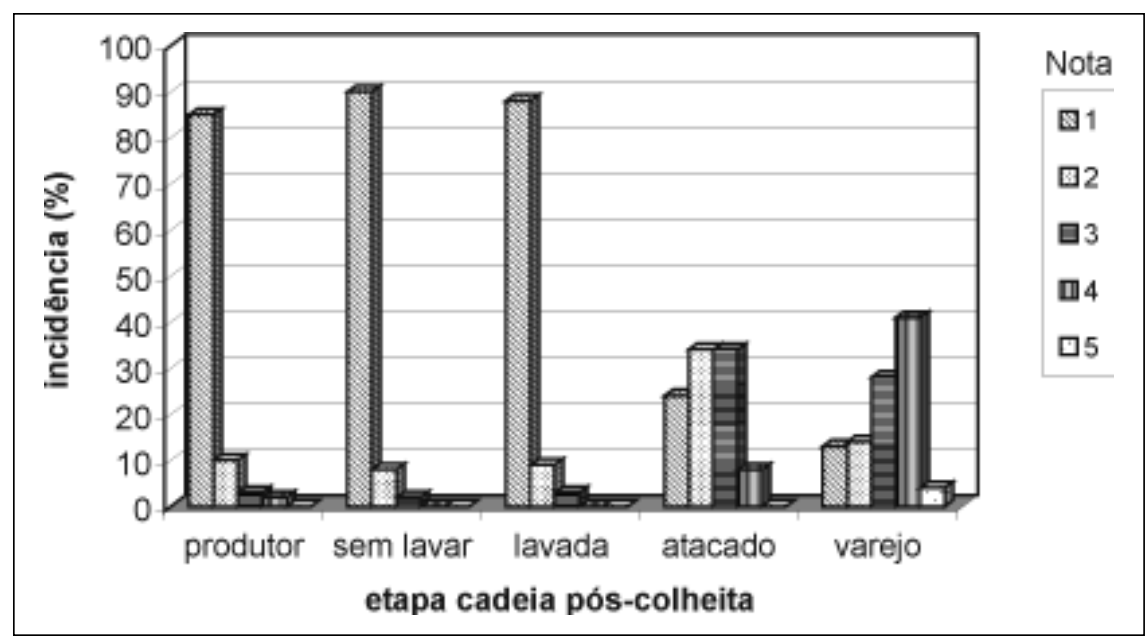

Figura 2. Incidência de lesão superficial causada por abrasão em raízes de mandioquinhasalsa em cinco etapas do manuseio de pós-colheita em São Paulo avaliada por meio de escala de notas ( $1=$ sem lesões; $5>40 \%$ área lesionada). Brasília-DF, Embrapa Hortaliças/ UnB-FAV, 2000-2001.

ocorrência dependendo das condições ambientais ou então ficar mais esbranquiçadas quando ocorre a suberização. Assim como constatado para a maçã (Ceponis et al., 1962), a incidência das lesões superficiais foi cumulativa à medida que a mandioquinhasalsa passava pelas sucessivas etapas da cadeia de pós-colheita.

A caracterização dos principais tipos de injúrias mecânicas e a identificação das etapas em que ocorrem são fundamentais para a proposição de medidas de redução de perdas (Peleg, 1985; Sargent, 1995). No caso da mandioquinha-salsa, a etapa mais crítica em relação à incidência de injúrias mecânicas das raízes ocorre entre o beneficiamento e a comercialização no atacado, onde são realizadas as operações de seleção, classificação, encaixotamento e carga das caixas no caminhão no galpão de beneficiamento, e transporte rodoviário, descarga e armazenamento temporário no atacado. A lesão superficial é o tipo de dano mecânico de incidência mais freqüente, sendo ocasionada principalmente pela fricção das raízes umas contra as outras e com as paredes da embalagem de madeira, muito ásperas.

Além de afetar a aparência das raízes e seu valor como produto, a incidência de injúrias mecânicas pode ter outras consequências, como uma maior probabilidade de infecção por fungos e bac- térias (Henz, 2001) e alterações fisiológicas, como a respiração e a síntese de etileno, e ainda modificações na cor, aroma, sabor e textura (Honório \& Moretti, 2002).

A incidência de injúrias mecânicas nas raízes de mandioquinha-salsa pode ser reduzida adotando-se medidas relativamente simples. No beneficiamento, recomenda-se a substituição das caixas de madeira do tipo " $K$ " por caixas de papelão ondulado ou plástico; utilizar um revestimento de papel, plástico ou outro tipo de material na parte interna da caixa de madeira para evitar o contato direto entre as raízes e a embalagem; e não encher demasiadamente as caixas com raízes. No transporte, recomendase manusear as caixas com mais cuidado nas operações de carga e descarga. No varejo, a manutenção das raízes em embalagens plásticas ou envoltas em filmes de PVC em balcões refrigerados $\left(3-5^{\circ} \mathrm{C}\right)$ é suficiente para minimizar os efeitos da injúria mecânica superficial porque as lesões não ficam escurecidas.

\section{AGRADECIMENTOS}

Os autores agradecem aos produtores de mandioquinha-salsa de CastroPR; aos beneficiadores de Tapiraí-SP; aos atacadistas Irmãos Senaga Ltda. e Comercial Sudeste Ltda. da CEAGESP, em São Paulo-SP; aos responsáveis pelos supermercados visitados em São 
Paulo-SP e Brasília-DF; aos técnicos do Centro de Qualidade em HorticulturaCEAGESP; ao atacadista Ki-Frutt, de Brasília-DF; e aos funcionários do Laboratório de Pós-Colheita da Embrapa Hortaliças.

\section{LITERATURA CITADA}

AMORIM, L. Avaliação de doenças. In: BERGAMIN FILHO, A.; KIMATI, H.; AMORIM, L. (eds.). Manual de Fitopatologia. São Paulo: Editora Agronômica Ceres, 1995. p. 647-671.

BOFF, P.; ZAMBOLIM, L.; RIBEIRO DO VALE, F.X. Escalas para avaliação de severidade da mancha-de-estenfílio (Stemphylium solani) em tomateiro. Fitopatologia Brasileira, Brasília, v. 16, n. 4, p. 280-283, 1991

CANTWELL, M.; MORDEN, G.; RUBATZKY, V.; CHEN, P. Tests to monitor carrot cracking and breaking susceptibility. Eucarpia, v. 91, p. 91-103, 1991.

CAPPELLINI, R.A.; CEPONIS, M.J.; LIGHTNER, G.W. Disorders in celery and carrot shipments to the New York market, 1972-1985. Plant Disease, v. 71, n. 11, p. 1054-1057, 1987. CASTRO, L.R.; CORTEZ, L.A.B.; JORGE, J.T. Influência da embalagem no desenvolvimento de injúrias mecânicas em tomates. Ciência e Tecnologia de Alimentos, v. 21, n. 1, p. 26-33, 2001.

CEAGESP. Classificação da mandioquinha-salsa. São Paulo: CQH/CEAGESP, 2002. 8 p. (folder). CEPONIS, M.J.; KAUFMAN, J.; RINGEL, S.M. Quality of prepackaged apples in New York City retail stores. Washington: USDA, 1962. $12 \mathrm{p}$. (AMS-461).

CHITARRA, M.I.F.; CHITARRA, A.B. Pós-Colheita de Frutos e Hortaliças. Lavras: ESAL/ FAEPE, 1990. $320 \mathrm{p}$.
FAO. Prevención de pérdidas de alimentos postcosecha: frutas, hortalizas, raices y tubérculos manual de capacitación. Roma: FAO, 1993. 183 p. HENZ, G.P. Perdas pós-colheita e métodos de manejo da podridão-mole causada por Erwinia chrysanthemi e Erwinia carotovora spp em raizes de mandioquinha-salsa. Brasília: Universidade de Brasília, 2001. 255 p. (Tese doutorado).

HONÓRIO, S.L.; MORETTI, C.L. Fisiologia póscolheita de frutas e hortaliças. In: CORTEZ, L.A.B.; HONÓRIO, S.L.; MORETTI, C.L. (ed.). Resfriamento de Frutas e Hortaliças. Brasília: Embrapa Informação Tecnológica, 2002. p. 59-81. KAYS, S.J. Postharvest Physiology of Perishable Plant Products. New York: Van Nostrand Reinhold, 1991. $532 \mathrm{p}$.

LANA, M.M.; MOITA, A.W.; NASCIMENTO, E.F.; SILVA, G.S.; MELO, M.F. Metodologia para quantificação e caracterização das perdas póscolheita de cenoura. Brasília: Embrapa Hortaliças, 1999a. 10 p. (Embrapa Hortaliças. Pesquisa em Andamento, 31).

LANA, M.M.; NASCIMENTO, E.F.; MOITA, A.W.; SOUZA, G.S.; MELO, M.F. Metodologia para quantificação e caracterização das perdas pós-colheita de pimentão. Brasília: Embrapa Hortaliças, 1999b. 8 p. (Embrapa Hortaliças. Pesquisa em Andamento, 37).

MELLO, S.C.M.; TAKATSU, A.; LOPES, C.A. Escala diagramática para avaliação da manchabacteriana do tomateiro. Fitopatologia Brasileira, Brasília, v. 22, n. 4, p. 447-448, 1997.

PELEG, K. Produce handling, packing and distribution. Westport: AVI Publishing, $1985.625 \mathrm{p}$. REIFSCHNEIDER, F.J.B; FURUMOTO, O.; FILGUEIRA, F.A.R. Illustrated key for the evaluation of early blight of potatoes. FAO Plant Protection, v. 32, n. 3, p. 91-93, 1984.

SARGENT, S.A. Maintaining quality of horticultural crops during harvest and handling operations. Gainesville: Florida Postharvest Horticulture Institute, 1995. 5 p.
SARGENT, S.A.; BRECHT, J.K.; ZOELLNER, J.J. Assessment of mechanical damage in tomato packing lines. Transactions of the ASAE, v. 30, n. 1, p. 630-634, 1989a.

SARGENT, S.A.; BRECHT, J.K.; ZOELLNER, J.J.; CHAU, K.V.; RISSE, L.A. Reducing mechanical damage to tomatoes during handling and shipment. Transactions of the ASAE, v. 30, n. 2, p. 714-719, 1989b.

SILVA, J.L.O. Perdas quantitativas da batata por danos mecânicos de colheita. Horticultura Brasileira, Brasília, v. 12, n. 1, p. 20, 1994. Resumo.

SILVA, J.L.O.; MARTON, L. Desperdício por danos mecânicos de impacto na colheita da batata. Horticultura Brasileira, Brasília, v. 11, n. 1, p. 99, 1993. Resumo

SMITH, O. Potatoes: production, storing, processing. The Avi Publishing Company: 1977. $775 \mathrm{p}$.

SOUZA, R.M. Avaliação da incidência de danos mecânicos na pós-colheita de raizes de mandioquinha-salsa (Arracacia xanthorrhiza Bancroft). Brasília: Universidade de Brasília, 2001. 69 p. (Tese mestrado)

STONEHOUSE, J. Assessment of Andean bean diseases using visual keys. Plant Pathology, v. 43, n. 3, p. 519-527, 1994.

THORNTON, R.E. Tuber mechanical damage. In: STEVENSON, W.E.; LORIA, R.; FRANC, G.D.; WEINGARTNER, D.P. (eds.). Compendium of Potato Diseases. St. Paul: APS Press, 2001. p. 9496.

WILLS, R.; McGLASSON, B,; GRAHAM, D.; JOYCE, D. Postharvest: an introduction to the physiology and handling of fruit, vegetables and ornamentals. Sidney: CAB International, 1998. $262 \mathrm{p}$.

WRIGHT, W.R.; BILLETER, B.A. Marketing losses of selected fruits and vegetables at wholesale, retail and consumer levels in the Chicago area. Washington: USDA/ARS, 1975. 23 p. (Market Research Report, 1017). 